\title{
Spatial Distribution of Foreign Direct Investment and Productivity Growth in Less Developed Regions of China
}

\author{
Yanqing Jiang \\ School of Economics and Finance, Shanghai International Studies University, Shanghai, China \\ Email: yiiang@shisu.edu.cn
}

Received 17 September 2014; revised 29 October 2014; accepted 10 November 2014

Copyright (C) 2014 by author and Scientific Research Publishing Inc. This work is licensed under the Creative Commons Attribution International License (CC BY). http://creativecommons.org/licenses/by/4.0/ cc) (i) Open Access

\begin{abstract}
This study examines how the spatial distribution of foreign direct investment (FDI) affects productivity growth in less developed regions of China. A systematic theoretical framework is set up concerning the potential effects of FDI capital via different channels. Following the theoretical framework, this study presents empirical evidence showing that FDI spillovers from the developed regions play a crucial role in enhancing productivity growth in the less developed regions. Empirical results also show that local FDI spillovers in less developed regions promote local productivity growth. In addition, FDI spillovers from less developed regions are not shown to have a significant effect on productivity growth in other less developed regions.
\end{abstract}

\section{Keywords}

Foreign Direct Investment, Productivity, Convergence, Spillover Effect

\section{Introduction}

Many developing countries exhibit continued enthusiasm for attracting foreign direct investment (FDI) from abroad. For China, the spectacular economic take-off is closely dependent on the country's opening up and increasing inflows of FDI. Before 1978, there were virtually no foreign-owned firms operating in China. In 1978 China initiated its economic reform and embraced the open-door policy, and since then the country has received large inflows of FDI, shifting from restrictive policies to permissive policies in the early 1980s, then to policies encouraging FDI in general in the mid-1980s, and to policies encouraging more high-tech and more capital-intensive FDI projects in the mid-1990s [1].

The take-off of FDI inflows in China occurred in 1993, since when China has the largest amount of FDI in- 
flows among the developing countries. By 2004, China had accumulated 500 billion US dollars in FDI inflows, which largely occurred via solely foreign-owned enterprises, joint ventures, and cooperative enterprises. However, FDI inflows in China are highly unevenly distributed across different regions [2] [3]. One prominent feature of FDI spatial distribution is that the coastal regions have by far the larger share of total FDI, compared with China's interior regions [4]. This broad spatial pattern of FDI distribution has remained fairly stable over time, with the share of the coastal regions being as large as 85 percent.

China's remarkably high growth rates since the 1980s and the huge influx of FDI has stimulated a lot of discussion in recent literature. Many studies have highlighted the role of FDI in promoting China's economic growth. However, while there has been an increasing body of literature, systematic treatments of the effects of FDI on China's development are quite limited. Specifically, few studies have been devoted to analyzing the spatial spillover effects of FDI on China's regional development and interregional inequality [5]-[7]. Analysis of the spatial pattern of FDI spillover effects contributes to a more comprehensive understanding of the role of FDI in China's growth and development. For a big developing country like China, it is important to determine whether the spatial distribution of FDI follows a substitution or a complementary pattern across different regions. While striking a balance between fast growth and inequality reduction is crucial for policy stability, the desirability of a liberal FDI policy hinges on the spatial pattern of the spillover effects of concentrated FDI on FDIscarce regions Therefore, analysis of the spatial pattern of FDI spillover effects improves our understanding of the tension between reduction of interregional inequality and overall economic growth in China.

To close a gap in the literature, in the present study we investigate how the spatial distribution of FDI affects productivity growth in less developed regions of China. We set up a systematic theoretical framework to distinguish the potential effects of FDI through different channels. Under such a theoretical framework, empirical work is then carried out. Among other findings, our results show that FDI spillovers from the relatively more developed regions play an important role in promoting productivity growth in the less developed regions of China.

This study is structured as follows. In Section 2, we provide a brief review of related literature. In Section 3 , we set up the theoretical framework and empirical model, on which our subsequent regression analysis will be based. In Section 4, we discuss various issues concerning the sample, variables and data. In Section 5, we carry out our regression analysis and present our estimation results. In Section 6, we discuss further issues and provide robustness checks. Section 7 concludes.

\section{Literature Review}

Empirical studies so far, at either country or firm level, usually support the view that FDI promotes economic growth by bring physical capital, advanced technology, as well as management expertise into the host country [6]. A representative country-level study, [8], examines the impact of FDI on economic growth in a cross-country regression framework. The study shows that a strong positive interaction exists between FDI and human capital, while the same interaction is insignificant in the case of domestic investment. Thus according to [8], FDI promotes economic growth only when the absorptive capacity of advanced technologies exceeds a certain threshold in the host economy. Likewise, another study, [9], when investigating how and to what extent knowledge capital and technology spillovers contribute to regional growth in China, finds that human capital is an important aspect of the capacity to absorb spillovers from FDI, and that the level of a region's absorptive ability plays a crucial role in absorbing external knowledge sources embodied in FDI and imports.

Micro-level mechanisms of the growth effects of FDI are the focus of firm-level studies. Some of such studies often do not find a significant contribution of FDI to productivity growth of domestic firms in the same industry. For example, [10] finds no evidence supporting the existence of technology spillovers from foreign firms to domestic ones. The study of [11] shows that FDI has the predicted positive impact on productivity growth in recipient firms, but the magnitude of the spillover effect is quite small. The study of [12], in contrast to earlier work, finds that FDI leads to significant productivity gains in domestic firms. They provide a detailed account of why their results are different from those found in previous work.

A considerable number of studies support the existence of backward and forward externalities, which occur as foreign firms spread advanced technology via buying intermediate goods from upstream domestic suppliers or selling intermediate goods to downstream domestic firms [6]. Representative studies include [13]-[15]. Focusing on effects operating across industries, [13] presents evidence consistent with positive productivity spillovers 
from FDI taking place through interactions between foreign affiliates and local suppliers in upstream sectors. The study of [14], by examining both technological and linkage externalities, shows that FDI substitutes within-sector domestic investment but complements the latter across sectors, and therefore, the net effect on aggregate capital formation by host-country producers hinges on the interaction between linkages and spillovers. The study of [15], using a large panel of Chinese manufacturing firms, finds that FDI lowers the short-term productivity level but enhances long-term productivity growth in domestic firms of the same industry. The study also finds that externalities through backward and forward linkages have similar effects on productivity in domestic firms.

Some studies take account of the technology gap between domestic and foreign firms. Representative studies include [16]-[20]. The study of [16] finds that the technology spillovers are not determined solely by foreign presence, but rather by the interactions between foreign and domestic firms. The study of [17] shows how the quality of technology transferred through FDI is linked, through the technology gap, to innovation and imitation when the absorptive capacity of less developed countries is limited. The study of [18] finds that firms with low productivity relative to the sector average, or in low-skill, low foreign competition sectors gain less through FDI spillovers from foreign firms. The study of [19] shows evidence for a U-shaped relationship between domestic productivity growth and FDI interacted with absorptive capacity. The study of [20], however, finds that there exists a minimum absorptive capacity threshold level below which productivity spillovers from FDI are negligible or even negative.

Many studies focus on spatial spillover effects of FDI. The study of [21] finds that domestic firms gain from the presence of foreign firms in the same sector and region, but "loose out" if the firms are located in a different region but in the same sector. The study of [22] finds that FDI promotes the performance of private domestic firms but not that of state-owned enterprises in China. The study of [23] examines whether state-owned enterprises in China have benefited from the technical and managerial skills possessed by multinational firms operating in the country, and find that the evidence for positive spillovers is not overwhelming.

However, regional FDI studies often show that within the host country, the spatial concentration of FDI may aggravate unbalanced development, widening the income gap between developed and under-developed regions [6]. For example, [24] finds that coastal development benefits in an unequal way to inland regions. The study of [25] shows that the spatial pattern of FDI has a significant impact on the widening interregional income gap in China. Similarly, [26] shows that even after netting out the effects of many other important factors, foreign trade and FDI are still two important factors contributing to the widening interregional inequality in China. The study of [27] investigate the location choices of foreign investors and find that the concentration of FDI in a few relatively developed regions may prevent the effects of FDI from spreading to the less developed regions of the host country.

\section{The Basic Model}

Based on existing literature, our present study empirically examines the role of the interregional pattern of FDI distribution in shaping productivity growth in less developed regions in China. Specifically, this study contributes to the literature by presenting empirical evidence supporting the existence of a significant spillover effect of FDI inflows in the more developed coastal regions on productivity growth of the less developed non-coastal regions in China.

In this section, we build our basic theoretical model, on which subsequent empirical analysis will be based. We adopt a Cobb-Douglas aggregate production function of the form

$$
Y_{i}(t)=A_{i}(t) K_{i}(t)^{\alpha} H_{i}(t)^{1-\alpha}
$$

where $i$ indexes a less developed region (i.e. a non-coastal region) in China ${ }^{1} . Y_{i}$ is regional output, $A_{i}$ is the level of regional total factor productivity (TFP), $K_{i}$ is regional stock of physical capital (including domestic and foreign-invested physical capital together), and $H_{i}$ is our measure of regional human capital stock. Let $L_{i}$ be the total number of regional workers and define per worker human capital stock as $h_{i} \equiv H_{i} / L_{i}$. Equation (1) can then be written intensively as

$$
y_{i}(t)=A_{i}(t) k_{i}(t)^{\alpha} h_{i}(t)^{1-\alpha}
$$

${ }^{1}$ In this study, a less developed region (province) in China refers to a non-coastal region (province) in China. 
for which we define $y_{i} \equiv Y_{i} / L_{i}$ and $k_{i} \equiv K_{i} / L_{i}$ as per worker output and per worker physical capital stock, respectively. Equation (2) immediately leads to

$$
\ln y_{i}(t)=\ln A_{i}(t)+\alpha \ln k_{i}(t)+(1-\alpha) \ln h_{i}(t)
$$

By which we can calculate the level of regional TFP, $A_{i}$, as a residual once data on $y_{i}, k_{i}$ and $h_{i}$ are obtained.

We hypothesize that TFP growth in a less developed Chinese region is positively related to the size of the gap between its actual TFP level and its potential (target) TFP level at any given point in time. Technically, we assume

$$
\frac{\mathrm{d} \ln A_{i}(t)}{\mathrm{d} t}=\lambda\left[\ln A_{i}^{*}(t)-\ln A_{i}(t)\right]
$$

where $A_{i}^{*}(t)$ refers to the potential level of regional TFP at time $t$, and $\lambda$ is the rate of convergence in regional TFP. To model the effects of FDI on regional productivity growth, we further assume that potential TFP is governed by

$$
A_{i}^{*}(t)=X_{i} f_{i}(t)^{\pi} S_{i}(t)^{\mu} h_{i}(t)^{\omega} T(t)
$$

where $X_{i}$ encompasses a set of time-invariant, region-specific factors affecting potential TFP in region $i$, $f_{i}(t)$ measures the degree of direct exposure of region $i$ to FDI at time $t$ while $S_{i}(t)$ measures the degree of indirect exposure of region $i$ to FDI at time $t$ via other regions $j$ in China $(j \in Z$, where $Z$ is some subset of all the other Chinese regions, to be defined later), $h_{i}(t)$ measures regional per worker human capital stock as defined earlier, and $T(t)$ denotes the world frontier level of TFP, which is assumed to grow exogenously over time.

Plugging (5) into (4), we obtain

$$
\frac{\mathrm{d} \ln A_{i}(t)}{\mathrm{d} t}+\lambda \ln A_{i}(t)=\lambda\left[\ln X_{i}+\pi \ln f_{i}(t)+\mu \ln S_{i}(t)+\omega \ln h_{i}(t)+\ln T(t)\right]
$$

Multiplying (6) throughout by $\mathrm{e}^{\lambda t}$ gives

$$
\begin{aligned}
\int_{t_{1}}^{t_{2}} \mathrm{e}^{\lambda t}\left[\frac{\mathrm{d} \ln A_{i}(t)}{\mathrm{d} t}+\lambda \ln A_{i}(t)\right] \mathrm{d} t & =\ln X_{i} \int_{t_{1}}^{t_{2}} \lambda \mathrm{e}^{\lambda t} \mathrm{~d} t+\pi \int_{t_{1}}^{t_{2}} \lambda \mathrm{e}^{\lambda t} \ln f_{i}(t) \mathrm{d} t \\
& +\mu \int_{t_{1}}^{t_{2}} \lambda \mathrm{e}^{\lambda t} \ln S_{i}(t) \mathrm{d} t+\omega \int_{t_{1}}^{t_{2}} \lambda \mathrm{e}^{\lambda t} \ln h_{i}(t) \mathrm{d} t \\
& +\int_{t_{1}}^{t_{2}} \lambda \mathrm{e}^{\lambda t} \ln T(t) \mathrm{d} t
\end{aligned}
$$

Assuming $f_{i}(t), S_{i}(t)$ and $h_{i}(t)$ remain constant within the small interval $\left[t_{1}, t_{2}\right]$, we perform the integration in (7) and multiply throughout by $\mathrm{e}^{-\lambda t_{2}}$ to obtain the following

$$
\begin{aligned}
& \ln A_{i}\left(t_{2}\right)=\mathrm{e}^{-\lambda \tau} \ln A_{i}\left(t_{1}\right)+\pi\left(1-\mathrm{e}^{-\lambda \tau}\right) \ln f_{i}\left(t_{1}\right)+\mu\left(1-\mathrm{e}^{-\lambda \tau}\right) \ln S_{i}\left(t_{1}\right) \\
& +\omega\left(1-\mathrm{e}^{-\lambda \tau}\right) \ln h_{i}\left(t_{1}\right)+\left(1-\mathrm{e}^{-\lambda \tau}\right) \ln X_{i}+\mathrm{e}^{-\lambda t_{2}} \int_{t_{1}}^{t_{2}} \lambda \mathrm{e}^{\lambda t} \ln T(t) \mathrm{d} t
\end{aligned}
$$

where $\tau \equiv t_{2}-t_{1}$. Rearranging (8) gives

$$
\begin{aligned}
\ln A_{i}\left(t_{2}\right)-\ln A_{i}\left(t_{1}\right)= & -\rho \ln A_{i}\left(t_{1}\right)+\pi \rho \ln f_{i}\left(t_{1}\right)+\mu \rho \ln S_{i}\left(t_{1}\right) \\
& +\omega \rho \ln h_{i}\left(t_{1}\right)+\rho \ln X_{i}+\mathrm{e}^{-\lambda t_{2}} \int_{t_{1}}^{t_{2}} \lambda \mathrm{e}^{\lambda t} \ln T(t) \mathrm{d} t
\end{aligned}
$$

where $\rho \equiv\left(1-\mathrm{e}^{-\lambda \tau}\right)$. Using (3) above, (9) implies

$$
\begin{aligned}
\ln y_{i}\left(t_{2}\right)-\ln y_{i}\left(t_{1}\right)= & \alpha\left[\ln k_{i}\left(t_{2}\right)-\ln k_{i}\left(t_{1}\right)\right]+(1-\alpha)\left[\ln h_{i}\left(t_{2}\right)-\ln h_{i}\left(t_{1}\right)\right] \\
& -\rho \ln y_{i}\left(t_{1}\right)+\rho \alpha \ln k_{i}\left(t_{1}\right)+\rho(1-\alpha+\omega) \ln h_{i}\left(t_{1}\right) \\
& +\pi \rho \ln f_{i}\left(t_{1}\right)+\mu \rho \ln S_{i}\left(t_{1}\right)+\rho \ln X_{i}+\mathrm{e}^{-\lambda t_{2}} \int_{t_{1}}^{t_{2}} \lambda \mathrm{e}^{\lambda t} \ln T(t) \mathrm{d} t
\end{aligned}
$$

Equation (10) can be rewritten as a panel data regression specification in its conventional notations as follows 


$$
\begin{aligned}
\Delta \ln y_{i t}= & \alpha \Delta \ln k_{i t}+(1-\alpha) \Delta \ln h_{i t}-\rho \ln y_{i t}+\rho \alpha \ln k_{i t}+\rho(1-\alpha+\omega) \ln h_{i t} \\
& +\pi \rho \ln f_{i t}+\mu \rho \ln S_{i t}+x_{i}+\eta_{t}+\varepsilon_{i t}
\end{aligned}
$$

where the sign $\Delta$ is associated with the difference between the levels at the two time points $t_{2}$ and $t_{1}$. The term containing the integral in (10) is now subsumed into the time intercept $\eta_{t}$. The time-invariant term in (10) is now written as the region heterogeneity $x_{i}$. We add $\varepsilon_{i t}$ to the equation as the zero-mean idiosyncratic error term. Equation (11) constitutes the foundation for our empirical analysis in subsequent sections.

\section{The Variables and Data}

Our sample consists of 18 provincial-level non-coastal Chinese regions over the period 1997-2012. These noncoastal regions are Shanxi, Inner Mongolia, Jilin, Heilongjiang, Anhui, Jiangxi, Henan, Hubei, Hunan, Guangxi, Sichuan, Guizhou, Yunnan, Shaanxi, Gansu, Qinghai, Ningxia and Xinjiang ${ }^{2}$. The coastal regions concerned in this study (a possible choice of the set $Z$ ) are 10 provincial-level coastal Chinese regions, which are Beijing, Tianjin, Hebei, Liaoning, Shanghai, Jiangsu, Zhejiang, Fujian, Shandong and Guangdong ${ }^{3}$.

Before we obtain data on all the variables in (11), the two "FDI variables" in our regression specification, $f_{\text {it }}$ and $S_{i t}$, should be properly defined. The direct exposure variable, $f_{i t}$, is defined in a quiet straightforward way as follows

$$
f_{i t} \equiv \frac{F_{i t}}{Y_{i t}}
$$

where the numerator $F_{i t}$ denotes the capital stock of FDI of region $i$ at time $t$. The indirect exposure variable, $S_{i t}$, is defined in a more complicated way as follows

$$
\ln S_{i t} \equiv \sum_{j \in Z} \ln \left(w_{i j, t} \frac{F_{j t}^{\phi}}{Y_{i t}^{\sigma}}\right)
$$

where $F_{j t}$ denotes the capital stock of FDI in region $j(j \neq i, j \in Z$, where $Z$ is to be defined later $)$ at time $t$. The $w_{i j, t}$ stands for nonnegative weights that are specified a priori. These weights measure the relative importance of the regions $j$ in the process of domestic spatial FDI spillovers for any non-coastal region $i$ at time $t$. Rearranging (13) directly leads to

$$
\ln S_{i t}=\sum_{j \in Z} \ln w_{i j, t}+\phi \sum_{j \in Z} \ln F_{j t}-\sigma \sum_{j \in Z} \ln Y_{i t}
$$

Inserting (12) and (14) back into (11) yields

$$
\begin{aligned}
\Delta \ln y_{i t}= & \alpha \Delta \ln k_{i t}+(1-\alpha) \Delta \ln h_{i t}-\rho \ln y_{i t}+\rho \alpha \ln k_{i t}+\rho(1-\alpha+\omega) \ln h_{i t} \\
& +\pi \rho \ln \left(F_{i t} / Y_{i t}\right)+\mu \rho \sum_{j \in Z} \ln w_{i j, t}+\mu \rho \phi \sum_{j \in Z} \ln F_{j t}-\mu \rho \sigma \sum_{j \in Z} \ln Y_{i t} \\
& +x_{i}+\eta_{t}+\varepsilon_{i t}
\end{aligned}
$$

Which can be estimated using a nonlinear least squares method once data on the relevant variables are obtained.

We need to obtain data on the variables in (15), which are regional output $Y_{i t}$ and regional per worker output $y_{i t}$, regional per worker physical capital stock $k_{i t}$, regional per worker human capital stock $h_{i t}$, and regional FDI capital stock $F_{i t}$ and $F_{j t}$. Panels of the size of regional employment (i.e. the number of workers), regional nominal Gross Regional Product (GRP) and GRP indices are directly available from the official publications of the National Bureau of Statistics of China, so that values of $Y_{i t}$ (i.e. real GRP) and $y_{i t}$ (i.e. real per worker GRP) can be calculated. Data on domestic and foreign investments are also available from the various official publications of the National Bureau of Statistics of China. However, these publications do not directly record capital stock data. Therefore, we use the perpetual inventory method (PIM) to calculate the relevant le-

\footnotetext{
${ }^{2}$ Owing to missing data, two inland regions, Tibet and Chongqing, are not included.

${ }^{3}$ One coastal province, Hainan, is not included owing to missing data.
} 
vels of domestic and FDI capital stock. In doing so, we follow [28] and adopt a universal annual depreciation rate of 9.6 percent for both domestic and FDI capital for all the regions throughout our sample period. By applying such a PIM procedure, data on $k_{i t}, F_{i t}$ and $F_{j t}$ can be obtained.

To get a feel of the spatial disparity in regional FDI capital stock, we present in Figure 1 the values of the coefficient of variation of regional per worker FDI stock across the 28 inland and coastal regions over 19972012. A general trend of the interregional disparity in FDI stock is that the spatial disparity, as reflected by the coefficient of variation, rises gradually during 1997-2001 and then declines steadily afterwards. Similarly, to see how the spatial disparities in regional per worker output and physical capital stock change over the same period of time, we present in Figure 2 the values of the coefficient of variation of the regional per worker output and per worker physical capital stock across the 28 regions. We see that, just like the trend shown in Figure 1, the coefficients of variation for both per worker output and per worker physical capital stock rise gradually during 1997-2001 and decline steadily during 2001-2012. In addition, during 2001-2012, the coefficient of variation for per worker physical capital stock declines more sharply than that for per worker output.

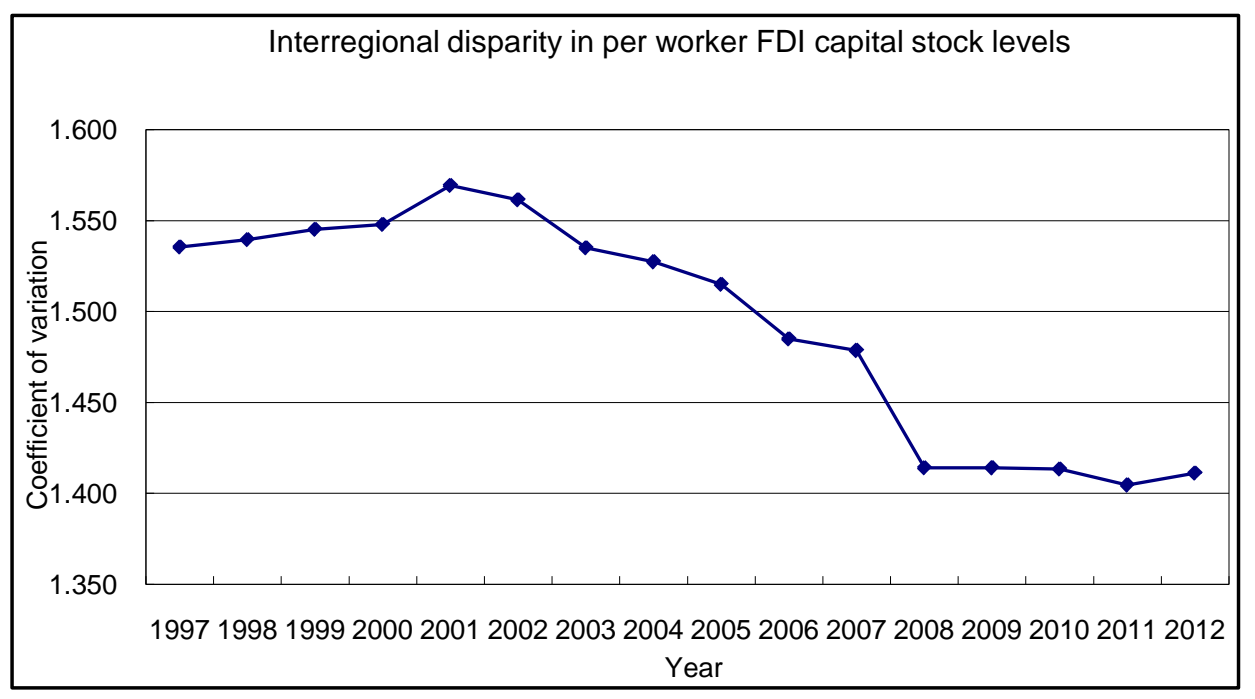

Figure 1. Interregional disparity in per worker FDI capital stock levels. The values of the coefficient of variation of regional per worker FDI capital stock across the 28 inland and coastal regions over 1997-2012 are shown in the figure.

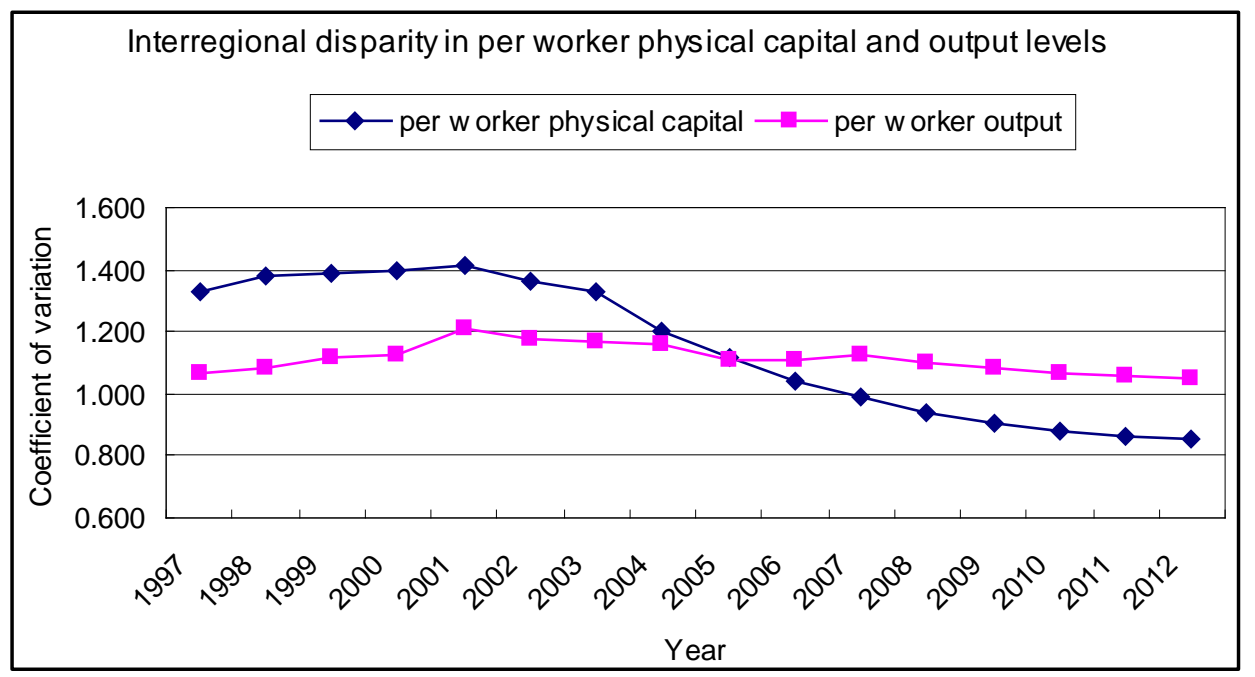

Figure 2. Interregional disparity in per worker physical capital and output. The values of the coefficients of variation of regional per worker physical capital stock and per worker output across the 28 inland and coastal regions over 1997-2012 are shown in the figure. 
We follow the basic method of [29] in obtaining data on regional per worker human capital stock $h_{i t}$. We assume that $h_{i t}$ is related to educational attainment by the function $\ln h_{i t}=\psi\left(E_{i t}\right)$ with $\psi(0)=0$, where $E_{i t}$ is the average number of years of education attained by a worker in the regional labor force. The derivative $\mathrm{d} \psi\left(E_{i t}\right) / \mathrm{d} E_{i t}$ is the return to schooling estimated in a Mincerian wage regression [30], with the rate of return being 13.4 percent, 10.1 percent and 6.8 percent respectively for schooling of the first four years, the second four years, and that beyond the eighth year [31]. Therefore, with this evidence, we can calculate the values of regional per worker human capital stock $h_{i t}$ based on regional data on educational attainment, which are also found in official publications of the National Bureau of Statistics of China. To get a feel of the spatial disparity in regional per worker human capital stock, we present in Figure 3 the values of the coefficient of variation of regional per worker human stock across the 28 inland and coastal regions over 1997-2012.

The weights $w_{i j, t}$ in (13)-(15) indicate the relative importance of the regions $j$ in the process of domestic interregional spillover of FDI for a less developed region $i$ at time $t$. In this study, we use the values of a domestic market integration index as the weights $w_{i j, t}$. The idea behind constructing the index is that the dispersion (across goods) of price differentials of identical goods between two regions can be an inverse indicator of the degree of market integration between the two regions [32]. To construct the market integration index by this price-based method, we follow the method of [33] and let $p_{i t}^{m}$ and $p_{j t}^{m}$ be the price of good $m$ respectively in regions $i$ and $j$ at time $t$. Then we can define

$$
D_{i j, t}^{m} \equiv \ln \left(\frac{p_{i t}^{m}}{p_{i, t-1}^{m}}\right)-\ln \left(\frac{p_{j t}^{m}}{p_{j, t-1}^{m}}\right)
$$

Which measures the difference in the percentage change of the price of good $m$ between regions $i$ and $j$ during the time interval $(t-1, t)$. The dispersion of $D_{i j, t}^{m}$ across a chosen set of goods can be an inverse indicator of the degree of market integration between regions $i$ and $j$ at time $t$. We calculate the variance of $D_{i j, t}^{m}$ across all the chosen goods for each region pair $(i, j)$ at time $t$. Any specific weight $w_{i j, t}$ in (13) can then be defined as

$$
w_{i j, t} \equiv\left[\operatorname{var}\left(D_{i j, t}\right)\right]^{-1 / 2}
$$

where we denote the variance of $D_{i j, t}^{m}$ as $\operatorname{var}\left(D_{i j, t}\right)$.

We need to choose a specific set of goods to construct (16) and (17). Considering data availability, the types of goods we choose are: grain; oil and fat; meat, poultry and related processed products; eggs; fish and shellfish; vegetables; fresh and dried fruit; tobacco; liquor; garments, clothing fabric; footwear and hats; durable consumer goods; daily use household articles; and cosmetics.

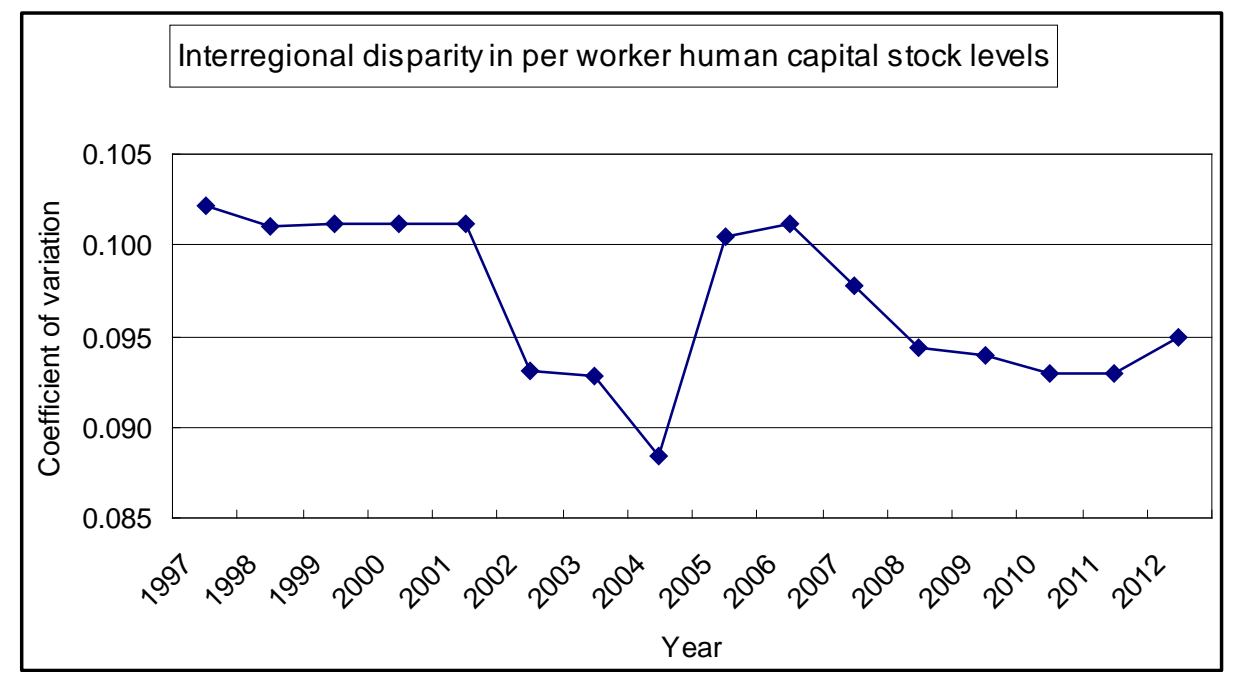

Figure 3. Interregional disparity in per worker human capital stock levels. The values of the coefficient of variation of regional per worker human capital stock across the 28 inland and coastal regions over 1997-2012 are shown in the figure. 


\section{Empirical Results}

To implement our econometric exercise based on (15), we divide our entire sample period 1997-2012 into five three-year sub-periods, which are 1997-2000, 2000-2003, 2003-2006, 2006-2009 and 2009-2012, respectively. Therefore in (15) the sign $\Delta$ now pertains to a time interval of three years. For example, when $t$ in $y_{i t}$ indexes the calendar year 1997, $\Delta \ln y_{i t}$ then refers to growth during the time interval 1997-2000 (and so on). As we divide the whole sample length into five sub-periods, the time intercept $\eta_{t}$ in (15) can then be practically replaced by four time dummy variables (each for one sub-period) plus a common intercept in our regression exercise. In addition, to take account of the unobserved region heterogeneity $x_{i}$ in (15), we include the full set of individual region dummies (i.e. 17 dummies for the 17 regions other than the arbitrarily chosen base region) in our regression.

We apply a nonlinear least squares method to estimate the parameters $\alpha, \rho$ (hence $\lambda$ ), $\pi, \mu, \omega, \phi$ and $\sigma$ in (15). The regression results are listed in Table 1 . In this regression, we define that the set $Z$ (the regions $j$ ) includes all the coastal and inland regions other than region $i$ in China (27 regions altogether). In Table 1, all of the estimated parameters have the expected positive sign and are significant (at the one-percent level or at the usual five-percent level). The estimated coefficient on $\Delta \ln k_{i t}$, i.e. the estimate of the output elasticity of physical capital $\alpha$, is 0.501 . This estimate of $\alpha$ falls in the very vicinity of its traditionally accepted values in the case of China, which are exactly around $0.50-0.60$. The estimated coefficient on $\ln y_{i t}$, the parameter $\rho$, is 0.290 , which is significantly lower than unity (so that $\mathrm{e}^{-\lambda \tau}$ is properly defined, remembering $\left.\rho \equiv\left(1-\mathrm{e}^{-\lambda \tau}\right)\right)$. The estimate implies that the annual convergence rate $\lambda$ is estimated to be 0.114 (where $\rho \equiv\left(1-\mathrm{e}^{-\lambda \tau}\right)$, in which $\tau=3$ in the current case). This result shows that the non-coastal regions exhibit significant conditional convergence in regional productivity over the sample period. Conditional convergence in TFP does not mean that all the regions concerned converge to a common TFP growth path, but that each region converges to its respective TFP growth path, which is captured by (5). Therefore, our result shows that each non-coastal region converges to its own target TFP level at an annual rate of 11.4 percent.

The estimates of the parameters $\pi, \mu$ and $\omega$, which are the elasticities of the potential TFP, $A_{i}^{*}(t)$, with respect to $f_{i}(t), S_{i}(t)$ and $h_{i}(t)$, are $0.160,0.053$ and 0.217 respectively, all of which have the expected positive sign and are significant. These results imply that FDI contributes to regional output through three distinct channels. One channel is that FDI capital stock affects regional output as a direct, accumulable factor of production. In our current study, FDI capital is included as part of $K_{i}(t)$ in the production function in (1). Therefore, FDI contributes to regional output growth as an accumulable production input through the "ln $k_{i t}$ " and " $\Delta \ln k_{i t}$ " terms in our regression model in (15). The second channel is that, besides the direct, static effect of local FDI as an accumulable production input, local FDI also exerts a spillover effect on regional TFP growth (by affecting the potential level of regional TFP as indicated by (5)). This spillover effect of local FDI is captured by the " $f_{i}(t)$ " term in (5) and the " $\ln f_{i t}$ " term in (11). Our results (i.e. the estimated magnitudes of $\rho$ and $\pi$ ) in Table 1 show that the spillover effect of an increase in local FDI capital stock by, say, 10 percent

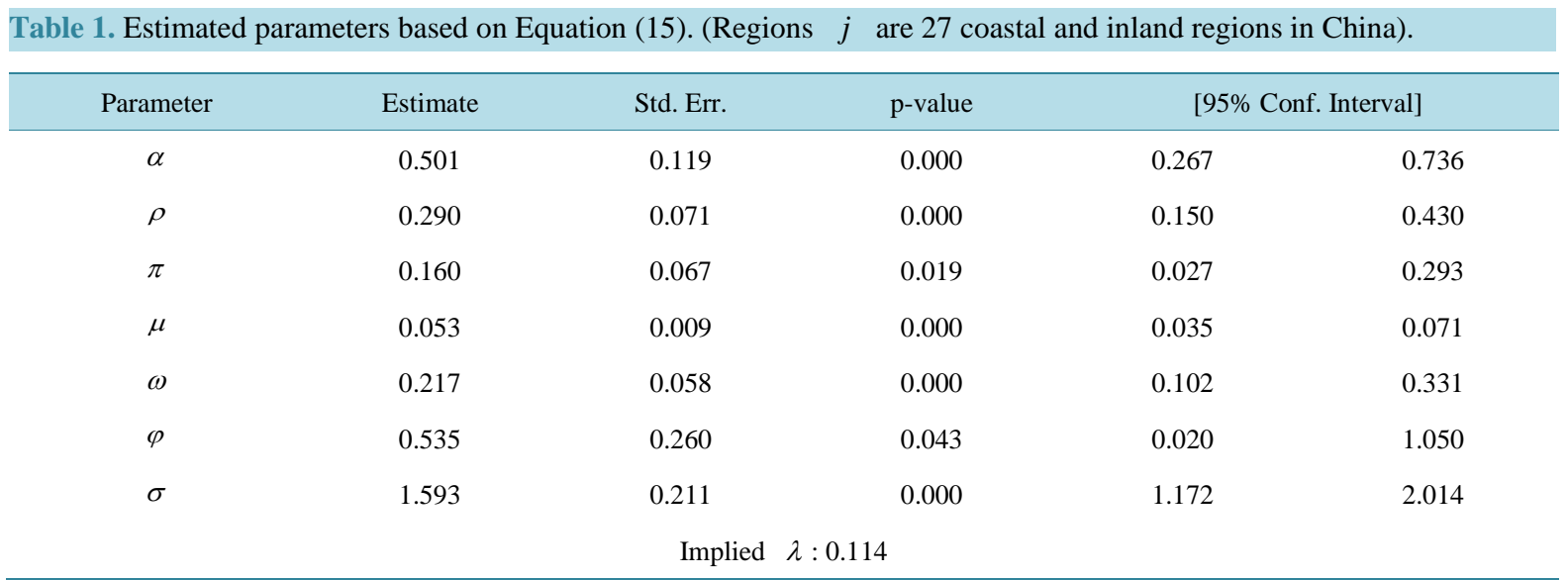

The sample includes 18 non-coastal province-level regions in China. The sample period is 1997-2012, divided into five equal-length sub-periods. The number of observations is 90 . To save space, the estimated intercepts, i.e. the common intercept, the coefficients on the time dummies, and the coefficients on the region dummies, are not reported in the table. 
would induce a faster local productivity growth by about 0.46 percentage points over a three-year interval, ceteris paribus (see (15)). Third, besides the two channels above, FDI in other regions (the regions $j$ ) also exerts a spatial spillover effect on regional TFP growth of a non-coastal region (also by affecting the potential level of regional TFP as indicated by (5)). This interregional spillover effect of FDI is captured in the " $S_{i}(t)$ " term in (5) and the " $\ln S_{i t}$ " term in (11). Our regression exercise thus provides a decomposition of the three channels of effects of FDI on output growth in non-coastal regions in China.

From these results, we can also see that human capital contributes to regional output through two different channels. One is that human capital affects output directly as an accumulable factor of production. This direct, static effect of human capital can be seen from the production function in (1) or its intensive form in (2). The other effect of human capital, which is an indirect, dynamic effect on output growth, is realized through its impact on regional TFP growth (as captured by (4) and (5) combined). According to our regression results, a 10 percent increase in the initial level of regional per worker human capital would lead to an instantaneous increase in regional per worker output of 4.99 percent (see (2)). However, combining (2) and (5), we see that in the long run, after the indirect, dynamic effect of a 10 percent one-time shock in regional per worker human capital has fully exhibited itself, regional per worker output would then increase by a total of 7.16 percent, which is larger than the static, an instantaneous increase in regional per worker output of 4.99 percent mentioned above.

The estimates of the parameters $\phi$ and $\sigma$ also have the expected positive sign and are significant. The estimated magnitude of the former, combined with those of $\mu$ and $\rho$, shows that higher FDI capital stock levels in all the regions $j$ (27 regions in the current case), say, by 10 percent, would, ceteris paribus, lead to faster growth of per worker output of an inland region (over a three-year interval) by about 2.2 percentage points (see (15)).

The regression in Table 1 shows that the interregional spillover effect of FDI is an important channel through which the overall spatial distribution of FDI inflows in China affects productivity growth in the less developed regions of China. In order to further investigate the spatial characteristics of the interregional FDI spillover effect, we rerun regressions according to (15), redefining the set of spillover source regions, i.e. the set $Z$ of all the regions $j$. By comparing estimation results obtained from variant regressions based on differentially defined sets of spillover source regions, we can hope to find out some important characteristics of the spatial pattern of the interregional FDI spillover effect on productivity growth in the less developed regions.

The results of our second regression, which is also run based on (15), are contained in Table 2. In this regression, we define that the set $Z$ (the spillover source regions $j$ ) includes only the coastal regions (10 of them altogether). In Table 2, again, all of the estimated parameters have the expected positive sign and are significant. The estimate of $\alpha$, which is 0.482 , is lower than that in Table 1 , but is still very close to its empirically accepted values in the case of China. The estimate of $\rho$ is 0.316 , a bit higher than that in Table 1 , resulting in a slightly higher implied value of the annual convergence rate $\lambda$, which is now 0.127 . The estimates of $\pi, \mu$ and $\omega$ are $0.181,0.064$ and 0.223 , all of which are slightly higher than those in Table 1, respectively. For $\phi$ and $\sigma$, the estimates are fairly close to their previous estimates in Table 1 too. The estimated magnitudes of

\begin{tabular}{|c|c|c|c|c|c|}
\hline Parameter & Estimate & Std. Err. & p-value & \multicolumn{2}{|c|}{ [95\% Conf. Interval] } \\
\hline$\alpha$ & 0.482 & 0.114 & 0.000 & 0.254 & 0.709 \\
\hline$\rho$ & 0.316 & 0.078 & 0.000 & 0.162 & 0.470 \\
\hline$\pi$ & 0.181 & 0.073 & 0.015 & 0.036 & 0.326 \\
\hline$\mu$ & 0.064 & 0.011 & 0.000 & 0.043 & 0.086 \\
\hline$\omega$ & 0.223 & 0.060 & 0.000 & 0.103 & 0.343 \\
\hline$\varphi$ & 0.557 & 0.274 & 0.046 & 0.011 & 1.103 \\
\hline$\sigma$ & 1.388 & 0.188 & 0.000 & 1.014 & 1.762 \\
\hline
\end{tabular}

The sample includes 18 non-coastal province-level regions in China. The sample period is 1997-2012, divided into five equal-length sub-periods. The number of observations is 90 . To save space, the estimated intercepts, i.e. the common intercept, the coefficients on the time dummies, and the coefficients on the region dummies, are not reported in the table. 
$\rho$ and $\pi$ in Table 2 show that the spillover effect of an increase in local FDI capital stock by 10 percent would induce a faster local productivity growth by about 0.57 percentage points over a three-year interval, ceteris paribus (see (15) again). The estimated magnitudes of $\mu, \rho$ and $\phi$ together suggests that higher FDI capital stock levels in all the regions $j$ (10 coastal regions now) by 10 percent would, holding other factors constant, lead to faster growth of per worker output of an inland region (over a three-year interval) by about 1.15 percentage points. In sum, none of the results presented by Table 2 and their implications are significantly different from those given by Table 1.

The results of our third regression based on (15) are summarized in Table 3. In this third regression, the spillover source regions (i.e. the set $Z$ ) are defined, instead, as all the other non-coastal regions in China (17 regions altogether). In Table 3, all the estimates of the parameters have the expected positive sign and most of them are significant. The estimate of $\alpha$ is 0.514 , very close to those values estimated from the previous two regressions. The estimate of $\rho$ is 0.285 , which is only slightly lower than those in Table 1 and Table 2, resulting in an implied annual rate of convergence of 0.112. The estimates of $\pi, \mu$ and $\omega$ are 0.177, 0.024 and 0.209, of which the estimate of $\mu$ is much lower than those in Table 1 and Table 2, and is not significantly greater than zero at the usual five-percent significance level. The estimates of $\phi$ and $\sigma$ are not far from those in Table 1 and Table 2, but that of $\phi$ is not significantly positive at the five-percent level. Different from the earlier regressions, this regression does not produce significantly positive estimates of $\mu$ and $\phi$, both of which are associated with the interregional spillover effect of FDI.

In sum, seen from the results of the three regressions in Tables 1-3, which use differentially defined sets of the spillover source regions $j$, one important characteristic of the spatial pattern of the interregional FDI spillover effect in China is that FDI capital in the coastal regions exerts a significant spillover effect on productivity growth of the interior regions, but FDI capital in other interior regions does not show a significant spillover effect on productivity growth of any interior region.

\section{Robustness Checks}

The regression exercise in the preceding section is critically dependent on the nonlinear least squares method we have used, which is in turn applied based on the regression specification in (15). We are interested in seeing whether alternative regression methods would lead to essentially the same empirical results as those obtained above. Following the nonlinear least squares method, the three regressions in Tables 1-3 generate estimates of the output elasticity of physical capital $\alpha$ that are very close to its empirically accepted values (around 0.50 ) for China. Therefore, we can now assume $\alpha=0.50$ a priori, and estimate the parameters involved in our model by applying various regression methods based on the following the specification

$$
\begin{aligned}
\Delta \ln A_{i t}= & -\rho \ln A_{i t}+\rho \omega \ln h_{i t}+\pi \rho \ln \left(F_{i t} / Y_{i t}\right)+\mu \rho \sum_{j \in Z} \ln w_{i j, t} \\
& +\mu \rho \phi \sum_{j \in Z} \ln F_{j t}-\mu \rho \sigma \sum_{j \in Z} \ln Y_{i t}+x_{i}+\eta_{t}+\varepsilon_{i t}
\end{aligned}
$$

Table 3. Estimated parameters based on Equation (15). (Regions $j$ are 17 inland regions in China).

\begin{tabular}{cccccc}
\hline Parameter & Estimate & Std. Err. & p-value & [95\% Conf. Interval] \\
\hline$\alpha$ & 0.514 & 0.115 & 0.000 & 0.285 & 0.743 \\
$\rho$ & 0.285 & 0.073 & 0.000 & 0.140 & 0.430 \\
$\pi$ & 0.177 & 0.068 & 0.011 & 0.041 & 0.313 \\
$\mu$ & 0.024 & 0.012 & 0.058 & -0.001 & 0.048 \\
$\omega$ & 0.209 & 0.055 & 0.000 & 0.100 & 0.318 \\
$\varphi$ & 0.483 & 0.244 & 0.051 & -0.002 & 0.968 \\
$\sigma$ & 1.646 & 0.213 & 0.000 & 1.222 & 2.070 \\
\end{tabular}

The sample includes 18 non-coastal province-level regions in China. The sample period is 1997-2012, divided into five equal-length sub-periods. The number of observations is 90 . To save space, the estimated intercepts, i.e. the common intercept, the coefficients on the time dummies, and the coefficients on the region dummies, are not reported in the table. 
Which is derived directly from (15) by applying (3), where the values of TFP are calculated as a residual assuming $\alpha=0.50$ a priori.

To check the robustness of our earlier empirical results, we run regressions based on (18) and compare the new results with our earlier ones. We perform a least squares dummy variables (LSDV) method to estimate the parameters according to (18). The LSDV regressions produce results that are fairly close to those summarized in Tables 1-3. Next, we shift the assumed value of $\alpha$ from $\alpha=0.50$ to $\alpha=0.45$ and $\alpha=0.55$ (respectively) to see whether such a shift leads to regression results that are significantly different from our prior ones. By following the same LSDV procedure, we find that these changes in the assumed value of $\alpha$ do not alter our prior empirical results in any significant ways. Further, we apply an alternative regression method, which is an extended GMM procedure proposed by [34], to see whether it generates results that deviates significantly from those obtained from the LSDV method used above. It turns out that the GMM regressions do not produce very precise estimates of the parameters. Many of the estimates are statistically insignificant, though most of them have the expected positive sign ${ }^{4}$.

One issue our models in (15) and (18) leave out is the potential interaction between FDI and human capital. The effects of FDI (local or in other regions) on local productivity growth may well be dependent on the level of local (per worker) human capital. To check the existence of the interactive effects of FDI and human capital, we run regressions based on the following specification

$$
\begin{aligned}
\Delta \ln A_{i t}= & \beta_{1} \ln A_{i t}+\beta_{2} \ln f_{i t}+\beta_{3} \ln S_{i t}+\beta_{4} \ln h_{i t}+\beta_{5} \ln A_{i t} \ln h_{i t} \\
& +\beta_{6} \ln f_{i t} \ln h_{i t}+\beta_{7} \ln f_{i t} \ln h_{i t}+x_{i}+\eta_{t}+\varepsilon_{i t}
\end{aligned}
$$

in which the variable $f_{i t}$ is constructed according to (12), $S_{i t}$ is constructed according to (13) with the estimated values of $\phi$ and $\sigma$ in Table 2 inserted, and the values of $A_{i t}$ are calculated in the same way as above assuming $\alpha=0.50$. To take account of the potential interactive effects, we include various interaction terms associated with human capital in (19). LSDV and GMM regressions are run based on (19). Our results show that the effects of the interaction terms are insignificant, either separately or jointly. This finding supports the appropriateness of our regression specifications in (15) and (18).

Another issue with our models in (15) and (18) is that the models do not explicitly consider regional institutional environment as a potential factor affecting regional productivity growth (and therefore do not explicitly include it as a control variable in the specifications). This regional institutional environment may include factors such as preferential policies from the central government, regulations of the local governments, and access to financial institutions, all of which are likely to influence local productivity growth. The time-constant region heterogeneity term $x_{i}$ in (15) and (18) captures only "permanent" regional features; it does not capture time-variant factors that constitute the changing regional institutional environment. We are thus interested in seeing whether our empirical results are sensitive to the inclusion of time-varying institutional factors in our regression model. Owing to the lack of direct measures, we use the relative size of the non-state-owned sector (in terms of both the labor share and the investment share) as a proxy variable for institution quality, hoping that this measure is able to reflect the level of flexibility of government policy and accessibility to financial institutions in any certain region ${ }^{5}$. It turns out that the inclusion of the institution quality variable does not significantly affect our prior regression results.

\section{Concluding Remarks}

Analysis of the spatial pattern of FDI spillover effects provides a better understanding of the role of FDI in China's growth and development. Specifically, it is important to see whether the spatial distribution of FDI follows a substitution or a complementary pattern across different Chinese regions. The desirability of a liberal FDI policy is dependent on the spatial pattern of the spillover effects of concentrated FDI on FDI-scarce regions. Therefore, analysis of the spatial pattern of FDI spillover effects improves our understanding of the tension between reduction of interregional inequality and overall economic growth in China.

This study investigates how the spatial distribution of FDI affects productivity growth in less developed regions of China. In this study, we set up a systematic theoretical framework concerning the potential effects of

\footnotetext{
${ }^{4}$ Different variants of the GMM regressions are tried, depending on differently assumed endogeneity status of the explanatory variables. ${ }^{5}$ Data needed for computing the relative size of the non-state-owned sector can be found in official publications of the National Bureau of Statistics of China.
} 
FDI through different channels. Under such a theoretical framework, relevant empirical work is then carried out. The major contributions of this study are threefold. First, this study fills a lacuna in the literature by providing empirical evidence showing that the FDI spillover effect of the relatively more developed coastal regions plays a critical role in promoting productivity growth in the less developed interior regions of China. Our regression results suggest that, over a three-year interval, a 10-percent increase in FDI capital levels in the coastal regions would accelerate productivity growth in the interior regions by about 1.15 percentage points. Second, empirical results of this study confirm that local FDI inflows in less developed regions facilitate local productivity growth. It is estimated (in Table 2) that the spillover effect of an increase in local FDI capital stock by 10 percent would accelerate local productivity growth by about 0.57 percentage points over a three-year interval, ceteris paribus. Third, our empirical results show that FDI capital located in any less developed region does not produce a significant spillover effect on productivity growth in other less developed regions in China.

\section{Acknowledgements}

The author thanks the anonymous reviewers and the editors of the Journal for their helpful comments and suggestions.

\section{References}

[1] Fung, K.C., Iizaka, H. and Tong, S.Y. (2004) FDI in China: Policy, Recent Trend and Impact. Global Economic Review, 33, 99-130. http://dx.doi.org/10.1080/12265080408449850

[2] Yin, H. (2011) Characteristics of Inter-Regional Income Disparities in China. Social Sciences in China, 32, $123-144$. http://dx.doi.org/10.1080/02529203.2011.598305

[3] Zhu, S., Lai, M. and Fu, X. (2008) Spatial Characteristics and Dynamics of Provincial Total Factor Productivity in China. Journal of Chinese Economic and Business Studies, 6, 197-217. http://dx.doi.org/10.1080/14765280802028328

[4] Cheung, K. and Lin, P. (2004) Spillover Effects of FDI on Innovation in China: Evidence from the Provincial Data. China Economic Review, 15, 25-44. http://dx.doi.org/10.1016/S1043-951X(03)00027-0

[5] Zhang, K.H. (2006) Foreign Direct Investment and Economic Growth in China: A Panel Data Study for 1992-2004, Conference of WTO. China and Asian Economies, University of International Business and Economics, Beijing.

[6] Ouyang, P. and Fu, H. (2012) Economic Growth, Local Industrial Development and Inter-Regional Spillovers from Foreign Direct Investment: Evidence from China. China Economic Review, 23, 445-460. http://dx.doi.org/10.1016/j.chieco.2012.03.005

[7] Madariaga, N. and Poncet, S. (2007) FDI in Chinese Cities: Spillovers and Impact on Growth. The World Economy, 30, 837-862. http://dx.doi.org/10.1111/j.1467-9701.2007.01025.x

[8] Borensztein, E., De Gregorio, J. and Lee, J. (1998) How Does Foreign Direct Investment Affect Economic Growth? Journal of International Economics, 45, 115-135. http://dx.doi.org/10.1016/S0022-1996(97)00033-0

[9] Kuo, C. and Yang, C. (2008) Knowledge Capital and Spillover on Regional Economic Growth: Evidence from China. China Economic Review, 19, 594-604. http://dx.doi.org/10.1016/j.chieco.2008.06.004

[10] Aitken, B.J. and Harrison, A.E. (1999) Do Domestic Firms Benefit from Direct Foreign Investment? Evidence from Venezuela. American Economic Review, 89, 605-618. http://dx.doi.org/10.1257/aer.89.3.605

[11] Djankov, S. and Hoekman, B. (2000) Foreign Investment and Productivity Growth in Czech Enterprises. World Bank Economic Review, 14, 49-64. http://dx.doi.org/10.1093/wber/14.1.49

[12] Keller, W. and Yeaple, S.R. (2009) Multinational Enterprises, International Trade, and Productivity Growth: FirmLevel Evidence from the United States. Review of Economics and Statistics, 91, 821-831. http://dx.doi.org/10.1162/rest.91.4.821

[13] Javorcik, B.S. (2004) Does Foreign Direct Investment Increase the Productivity of Domestic Firms? In Search of Spillovers through Backward Linkages. American Economic Review, 94, 605-627. http://dx.doi.org/10.1257/0002828041464605

[14] Kugler, M. (2006) Spillover from Foreign Direct Investment: Within or between Industries. Journal of Development Economics, 80, 444-477. http://dx.doi.org/10.1016/j.jdeveco.2005.03.002

[15] Liu, Z.Q. (2008) Foreign Direct Investment and Technology Spillovers: Theory and Evidence. Journal of Development Economics, 85, 176-193. http://dx.doi.org/10.1016/j.jdeveco.2006.07.001

[16] Kokko, A. (1996) Productivity Spillovers from Competition between Local Firms and Foreign Affiliates. Journal of International Development, 8, 517-530. 
http://dx.doi.org/10.1002/(SICI)1099-1328(199607)8:4<517::AID-JID298>3.0.CO;2-P

[17] Glass, A.J. and Saggi, K. (1998) International Technology Transfer and the Technology Gap. Journal of Development Economics, 55, 369-398. http://dx.doi.org/10.1016/S0304-3878(98)00041-8

[18] Girma, S., Greenaway, D. and Wakelin, K. (2001) Who Benefits from Foreign Direct Investment in the UK? Scottish Journal of Political Economy, 48, 119-133. http://dx.doi.org/10.1111/1467-9485.00189

[19] Girma, S. and Görg, H. (2002) Foreign Direct Investment, Spillovers and Absorptive Capacity: Evidence from Quantile Regressions. GEP Research Paper 02/14, University of Nottingham, Nottingham.

[20] Girma, S. (2005) Absorptive Capacity and Productivity Spillovers from FDI: A Threshold Regression Analysis. Oxford Bulletin of Economics and Statistics, 67, 281-306. http://dx.doi.org/10.1111/j.1468-0084.2005.00120.x

[21] Girma, S. and Wakelin, K. (2002) Are There Regional Spillovers from FDI in the UK? GEP Research Paper, No. 16, University of Nottingham, Nottingham.

[22] Hale, G. and Long, C. (2006) FDI Spillovers and Firm Ownership in China: Labor Markets and Backward Linkages. Federal Reserve Bank of San Francisco Working Paper Series No. 25, San Francisco.

[23] Girma, S. and Gong, Y. (2008) FDI, Linkages and the Efficiency of State-Owned Enterprises in China. Journal of Development Studies, 44, 728-749. http://dx.doi.org/10.1080/00220380802009233

[24] Brun, J., Combes, J. and Renard, M. (2002) Are There Spillover Effects between Coastal and Non-Coastal Regions in China? China Economic Review, 13, 161-169. http://dx.doi.org/10.1016/S1043-951X(02)00070-6

[25] Fujita, M. and Hu, D. (2001) Regional Disparity in China 1985-1994: The Effects of Globalization and Economic Liberalization. Annals of Regional Science, 35, 3-37. http://dx.doi.org/10.1007/s001680000020

[26] Zhang, X.B. and Zhang, K. (2003) How Does Globalisation Affect Regional Inequality within a Developing Country? Evidence from China. Journal of Development Studies, 39, 47-67. http://dx.doi.org/10.1080/713869425

[27] Nunnenkamp, P. and Stracke, R. (2007) Foreign Direct Investment in Post-Reform India: Likely to Work Wonders for Regional Development? Kiel Institute of World Economics Working Paper No.1375, Kiel.

[28] Zhang, J. (2008) Estimation of China’s Provincial Capital Stock (1952-2004) with Applications. Journal of Chinese Economic and Business Studies, 6, 177-196. http://dx.doi.org/10.1080/14765280802028302

[29] Hall, R.E. and Jones, C.I. (1999) Why Do Some Countries Produce So Much More Output per Worker than Others? Quarterly Journal of Economics, 114, 83-116. http://dx.doi.org/10.1162/003355399555954

[30] Mincer, J. (1974) Schooling, Experience, and Earnings. Columbia University Press, New York.

[31] Psacharopoulos, G. (1994) Returns to Investment in Education: A Global Update. World Development, 22, $1325-1343$. http://dx.doi.org/10.1016/0305-750X(94)90007-8

[32] Parsley, D.C. and Wei, S. (2001) Limiting Currency Volatility to Stimulate Goods Markets Integration: A Price Based Approach. NBER Working Paper No. 8468, National Bureau of Economic Research.

[33] Sheng, B. and Mao, Q. (2011) Trade Openness, Domestic Market Integration, and Provincial Economic Growth in China: 1985-2008. The Journal of World Economy, 44-66.

[34] Blundell, R. and Bond, S. (2000) GMM Estimation with Persistent Panel Data: An Application to Production Functions. Econometric Reviews, 19, 321-340. http://dx.doi.org/10.1080/07474930008800475 
Scientific Research Publishing (SCIRP) is one of the largest Open Access journal publishers. It is currently publishing more than 200 open access, online, peer-reviewed journals covering a wide range of academic disciplines. SCIRP serves the worldwide academic communities and contributes to the progress and application of science with its publication.

Other selected journals from SCIRP are listed as below. Submit your manuscript to us via either submit@scirp.org or Online Submission Portal.
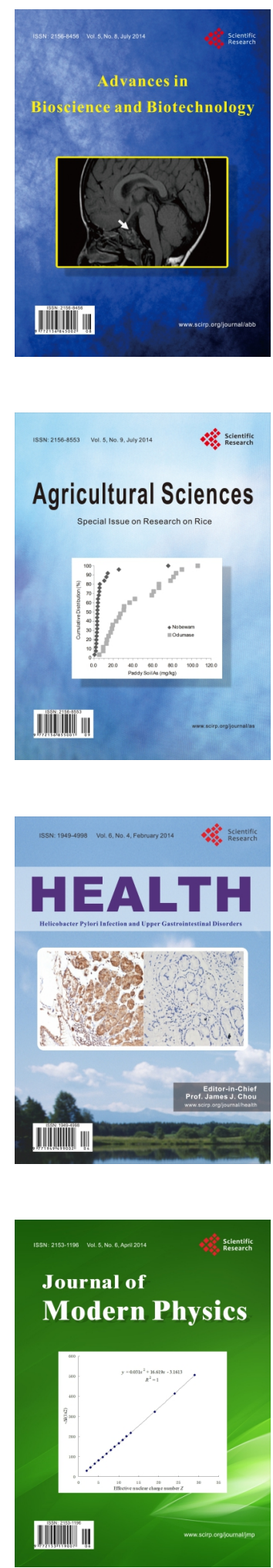
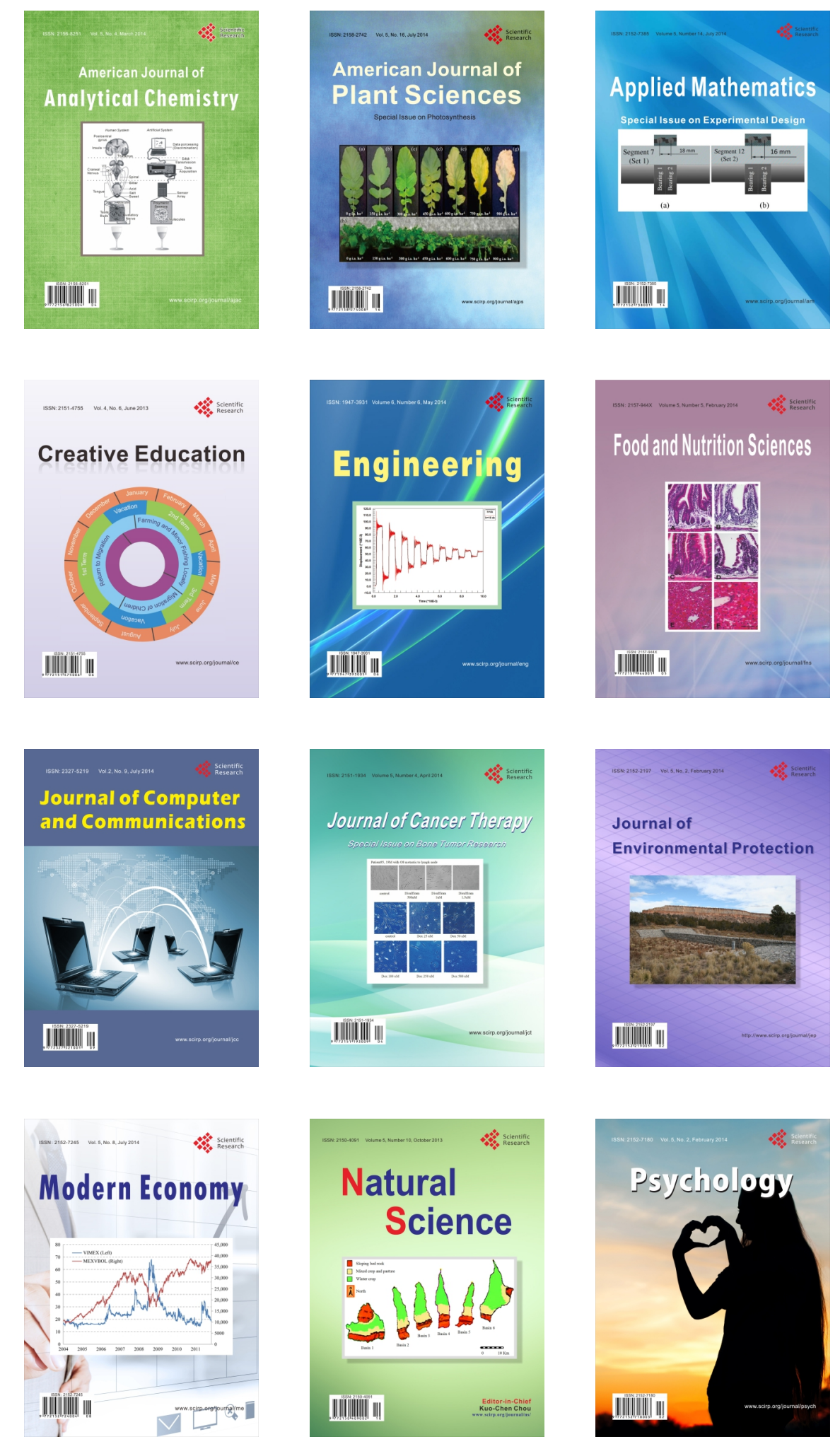